\title{
SER PROFESSOR NO SÉCULO XXI: AS REPRESENTAÇÕES SOCIAIS DE ALUNOS INGRESSANTES E CONCLUINTES DE UM CURSO DE PEDAGOGIA
}

\author{
Mayara Aparecida Pereira Menezes ${ }^{1}$, Augusta Boa Sorte O. Klebis ${ }^{1}$, Raimunda Abou Gebran ${ }^{2}$ \\ Universidade do Oeste Paulista - UNOESTE, ${ }^{1}$ Curso de Pedagogia. ${ }^{2}$ Programa de Mestrado em Educação, Presidente \\ Prudente, SP. E-mail:mayara_pmenezes@hotmail.com.br. Apoio: PIBIC/CNPq/UNOESTE
}

\section{RESUMO}

O presente artigo relata uma pesquisa que buscou trazer para o debate o papel das representações sociais na construção da identidade docente e como a formação inicial poderá contribuir para o fortalecimento desse processo, rumo a uma profissionalidade que atenda aos desafios atuais da docência. Assim, teve como objetivo geral realizar uma reflexão sobre as representações sociais de alunos ingressantes e concluintes do curso de pedagogia sobre o que é ser professor, no contexto atual, e sua relação com a construção da identidade docente. Mais especificamente buscou: a) comparar as representações sociais entre alunos ingressantes e concluintes do curso de Pedagogia; b) analisar a influência do contexto cultural, social e político educacional na construção dessas representações; c) refletir sobre o estabelecimento de um diálogo entre as representações sociais dos alunos e a qualidade da formação inicial ofertada pela instituição. Optou-se por uma pesquisa de campo de abordagem qualitativa, que se apoiou na Teoria das Representações Sociais (TRS) desenvolvida por Moscovici (2015) bem como na abordagem estrutural das representações- Teoria do Núcleo Central, proposta por Abric (1994). Os dados foram coletados por meio de um questionário e do Teste de Associação Livre de Palavras - TALP. A análise dos dados obtidos na pesquisa de campo, permite concluir que o curso de Pedagogia tem uma influência expressiva, na constituição da identidade docente. Dessa forma, se configura também como espaço de construção e reconstrução de representações sociais, que tendem a refletir, de forma positiva, no exercício da futura profissão.

Palavras - chave: Formação de Professores. Identidade docente. Representações Sociais. Formação Inicial

\section{BE TEACHER IN XXI CENTURY: THE SOCIAL REPRESENTATIONS OF STUDENTS FRESHMEN AND SENIORS OF A PEDAGOGY COURSE}

\begin{abstract}
The present paper reports a study that sought to bring to the debate the role of social representations in the construction of teacher identity and how the initial training can contribute to the strengthening of this process towards a professionalism that meets the current challenges of teaching. Thus, we aimed to carry out a reflection on the social representations of students, from the first and the final period of the Pedagogy graduating course, on what is to be a teacher, in the current context, and its relation to the construction of teacher's identity. More specifically, it sought to: a) compare the social representations among students entering and graduating in Pedagogy; b) analyze the influence of cultural, social and political-educational context in the construction of these representations; c) reflect upon the establishment of a dialogue between the social representations of students and the quality of initial training offered by the institution. We have chosen a qualitative approach of field research, which was based on the Social Representations Theory (SRT), developed by Moscovici (2015), as well as the structural approach of representations - Central Nucleus Theory (CNT)-, proposed by Abric (1994). The data were collected through a questionnaire and the Test WordsAssociation Test - WAT. The analysis of the data obtained in the field research allows us to conclude that the Pedagogy course has a significant influence on the constitution of the teacher identity. Thus, it is also configured as a space for construction and reconstruction of social representations, which tends to reflect positively in the course of future profession. Keywords: Teacher Training. Teacher identity. Social Representations. Initial formation
\end{abstract}




\section{INTRODUÇÃO}

Atualmente tem se constituído um grande desafio, a ser enfrentado pela educação no Brasil, atrair novas gerações para a carreira de professor. Por conseguinte, não se pode negar o desestímulo de muitos jovens à escolha de um curso de Licenciatura, bem como a desmotivação em exercer o magistério para muitos professores em exercício e, muitas vezes, em condições de grande precariedade, devido ao sucateamento das escolas. Aliada a tais condições os professores ainda enfrentam: salário indigno, jornada de trabalho estafante, plano de carreira não condizente com as necessidades atuais, além do desprestígio social e consequente imagem depreciativa veiculada pela mídia.

Nóvoa (1992) já dizia na década de 1990 que a crise da profissão docente se prolonga há vários anos e não há indícios e tampouco perspectivas de que será superada a curto prazo, e pelo que vivenciamos atualmente ainda há muita luta para que o professor seja, verdadeiramente, reconhecido e valorizado.

Ao refletir sobre o que significa ser professor no Brasil, nos atentamos para o fato de que identidade do sujeito em formação para a docência se constrói ao longo de sua trajetória de vida, de acordo com as experiências e expectativas dos diversos grupos do qual faz parte e se relaciona, por meio de um constante processo de interações. Desse modo a identidade docente é um processo de construção, desconstrução e reconstrução permanente, que comporta vivências e saberes pertencentes a cada pessoa, e que se estende durante toda a sua formação. Para Marcelo (2009), a reflexão sobre identidade profissional docente é muito relevante, pois, é por meio de nossa identidade, que nós nos percebemos, nos vemos e queremos que nos vejam.

Da mesma forma, Gebran e Trevisan (2015) afirmam não ser possível alcançar mudanças na educação, se a forma como os professores pensam for ignorada, assim como a forma como atuam, como representam seu trabalho e como as condições desse trabalho lhes permitem se posicionarem, criticamente, diante das práticas educativas propostas pelas reformas. As autoras ainda ressaltam que quando os sujeitos não têm consciência de suas representações, tendem a atuar orientados por práticas impostas culturalmente e historicamente, sem, no entanto, Ihes atribuir um sentido ou pertinência social. Quando isso ocorre, as representações se configuram como estereótipos a respeito do que os professores devem fazer e acabam impedindo que venham à tona as reais justificativas políticas e ideológicas de suas ações.

Nessa perspectiva, refletir sobre o que os alunos em processo de formação docente pensam a respeito do que é ser professor se torna relevante para avançarmos em direção a uma maior qualidade no ensino ofertado pelas instituições formadoras, em especial, pelo curso de pedagogia.

Tanto o sujeito que está iniciando a sua formação (ingressante) quanto o que está em concluindo (concluinte) uma licenciatura, tende a apresentar uma identidade docente futura intrínseca.

Por meio das Representações Sociais podemos inferir que há conhecimentos sobre o que é ser professor que não estão presentes na formação, mas que são inerentes a cada aluno, uma vez que as representações "circulam nos discursos, são carregadas pelas palavras, veiculadas nas mensagens e imagens mediáticas, cristalizadas nas condutas e agenciamentos materiais, espaciais" (JODELET, 1993, p.1). Tais conhecimentos estão presentes na cultura dos alunos, mas também nas experiências, nas ações, no diálogo e nas relações com o outro.

Dessa forma, esta pesquisa teve como objetivo geral realizar uma reflexão sobre as representações sociais de alunos ingressantes e concluintes do curso de pedagogia sobre o que é ser professor, no contexto atual, e sua relação com a construção da identidade docente. Mais especificamente buscou: a) comparar as representações sociais entre alunos ingressantes e concluintes de um curso de Pedagogia; b) analisar a influência do contexto cultural, social e político educacional na construção dessas representações; c) refletir sobre o estabelecimento de um diálogo entre as representações sociais dos alunos e a qualidade da formação inicial ofertada pela instituição.

\section{METODOLOGIA}

A pesquisa foi realizada em uma instituição particular de Ensino Superior, do Oeste Paulista. Os resultados apresentados tiveram como base um teste de associação livre 
de palavras -TALP e um questionário que possibilitou traçar um perfil dos participantes da pesquisa. Com o objetivo de investigar as representações sociais que os alunos ingressantes e concluintes possam ter sobre o que é ser professor na atualidade em diferentes momentos da graduação, foram aplicados questionários e o TALP, junto a 68 estudantes do Curso de Pedagogia, sendo 38 ingressantes (1은 termo) e 30 concluintes (70 termo).

A aplicação do questionário e do TALP ocorreu em sala de aula para todos que estavam presentes e se dispuseram a participar da pesquisa, após a apresentação do Termo de Consentimento Livre e Esclarecido - TCLE. O questionário compunha duas partes: I) Dados pessoais que buscou traçar o perfil socioeconômico dos alunos. II) Dados sobre a formação, que contemplou questões fechadas e discursivas que objetivaram investigar a formação acadêmica dos estudantes. As questões respondidas pelos participantes concluintes diferenciaram-se das questões respondidas pelos ingressantes. Uma vez que os concluintes já possuem, sem dúvida uma maior vivência e experiência em relação ao curso.

O teste de associação livre de palavras consistiu em solicitar ao participante que escrevesse as cinco primeiras palavras que the ocorresse ao ouvir a expressão indutora: ser professor hoje. Em seguida pedia-se que as enumerassem de acordo com uma ordem de importância. Finalmente, era solicitado que justificasse a escolha dessa palavra e que formasse uma frase utilizando a palavra escolhida, relacionando-a com o termo indutor "ser professor hoje". O tratamento dos dados obtidos pelo teste, foi realizado com o auxílio do software EVOC 2000, o qual identifica os possíveis elementos do núcleo central considerando a frequência $(F)$ e a ordem média de evocação (OME) ${ }^{1}$.

A execução do programa RANGFRQ, do software realiza uma tabela indicando as palavras mais centrais de uma representação, que dispõe rang $X$ frequência na qual em quatro quadrantes situam-se as palavras correspondentes a critérios baseados nos índices de sua frequência e a

\footnotetext{
${ }^{1} A$ frequência (F) de uma evocação é o somatório de suas frequências nas diversas posições; a frequência média (FM) é a média aritmética das diversas frequências obtidas por uma evocação. A ordem média de uma evocação (OME) é calculada pela média ponderada obtida mediante a atribuição de pesos diferenciados à ordem com que, em cada caso, uma dada evocação é enunciada (MAZZOTTI, 2007, p. 583).
}

ordem de posição. Dentro da tela do RANGFRQ encontram-se quatro espaços - quadrantes, onde: o quadrante superior à esquerda representa as palavras mais frequentes e citadas nos primeiros lugares, correspondente ao núcleo central. $\mathrm{O}$ quadrante superior à direita e inferior à esquerda compreendem as palavras em que há contradição entre o critério de posição (rang) e o da frequência, e representam a "periferia próxima" ao núcleo central. Por fim, o quadrante inferior à direita representa a periferia propriamente dita, onde aparecem as palavras de menor frequência e evocação mais tardia (MENIN; ZECHI, 2009).

Ressalta-se que para o desenvolvimento da pesquisa, fez-se necessário a aprovação da Coordenadoria de Pesquisa, Desenvolvimento e Inovação (CPDI) da Pró-Reitoria de Pesquisa e Pós-Graduação - protocolo 2525, e do Comitê de Ética e Pesquisa (CEP). Além disso a pesquisa está devidamente cadastrada na Plataforma Brasil protocolo 44528215.9.0000.5515.

\section{Entendendo as representações sociais}

Conforme Madeira (1998) apud

Guimarães (2005) as representações se constroem na história, por meio de um processo de relações familiares, grupais e intergrupais, que se prolonga por toda a vida, na qual se entrelaçam sentimentos, necessidades, valores, estereótipos, crenças, atitudes, imagens, normas.

As representações sociais são elaboradas e compartilhadas socialmente e influenciam diretamente na forma como os indivíduos e/ou os grupos sociais percebem a realidade, se comunicam e atuam. Para Guimarães (2005, p. 35-36):

As RS explicitam como um grupo se relaciona com um dado objeto social, servem de guia de ação, orientam a comunicação e a relação com o mundo e os outros. Também oferecem referencias para interpretação da realidade e favorecem a construção de valores, necessidades, interesses de um mesmo grupo. Diferentes grupos representam um mesmo objeto segundo uma forma própria. $\mathrm{O}$ conhecimento apreendido do objeto passa 
a fazer parte das conversas e aparece na forma de frases, visões, jargões, ditados, preconceitos, estereótipos, soluções, etc., tendo um efeito de realidade para 0 indivíduo.

De acordo com Moscovici (2015) as representações sociais são teorias do senso comum que são produzidas coletivamente nas interações sociais, sujeito-sujeito e sujeitoinstituição, cada qual no seu tempo, cultura e espaço específico, a fim de transformar o que é estranho em familiar, para assim compreender a realidade. Por conseguinte, na definição de Jodelet (1993), as representações sociais são fenômenos complexos que sempre estão ativos e atuando em nossa vida cotidiana. Para a autora, as representações sociais são identificadas como sistemas de interpretação, os quais orientam nossas relações com o mundo e com as pessoas, de tal modo que direciona e coordena as condutas e as comunicações sociais, além de interferir em diversos processos, como na transmissão e assimilação de conhecimentos, nas transformações sociais, no estabelecimento de identidades pessoais bem como sociais e expressões grupais.

Segundo Moscovici (2015), as RS são resultado da interação e comunicação, se formam e se configuram a qualquer momento, como consequência do equilíbrio específico dos processos de influência social. Deste modo, as define como:

Um sistema de valores, ideias e práticas, com uma dupla função: primeiro, estabelecer uma ordem que possibilita às pessoas orientar-se em seu mundo material, e social e controlálo; e em segundo lugar, possibilitar que a comunicação seja possível entre os membros de uma comunidade, fornecendoIhes um código para nomear e classificar, sem ambiguidade, os vários aspectos de seu mundo e da sua história individual e social (2015, p. 21).
Diante dessas definições pode-se observar que as representações sociais têm como base os valores dos grupos sociais, pois é por meio destes que surgem as significações, os conhecimentos científicos, as experiências, os valores culturais e ideológicos.

Partindo-se da premissa, pode-se afirmar que uma representação social é um conjunto organizado e estruturado, que sustenta informações, crenças, valores, opiniões e atitudes, constituindo um sistema sociocognitivo privado. Abric (1994) discorre que esse conjunto é composto de dois subsistemas que interagem entre si: um sistema central núcleo central e um sistema periférico. Sendo que é em torno do núcleo central que os elementos periféricos se encontram.

Conforme Guimarães (2005), Abric (1994) "é taxativo em afirmar a vinculação da teoria do núcleo central com a teoria geral das RS. Atesta que a noção de representação social a que se refere corresponde à teoria original elaborada em 1961 por Moscovici". Afirmando essa complementaridade, Flament (1989) apud Guimarães (2005), considera que a teoria do núcleo central é fundamentalmente capaz de tornar a teoria das representações sociais mais heurística para a prática social bem como para as pesquisas.

\section{A abordagem estrutural proposta por Jean Claud Abric}

De acordo com Pereira de Sá (1996) citado por Guimarães (2005), "a teoria do núcleo central resolveu o problema empírico das contradições presentes nas representações - são estáveis e mutáveis, rígidas e flexíveis, consensuais e individualizadas".

Conforme o que aponta Guimarães (2005), os elementos cognitivos do núcleo central apresentam as características da estabilidade, rigidez, consensualidade. Por conseguinte, os elementos periféricos possuem um caráter facilmente mutável, flexível e individualizado. 0 núcleo é responsável pelo significado global da representação e pela organização dos elementos periféricos. A periferia garante a interface com as práticas e situações do grupo.

Diante dessa proposição estrutural é importante destacar outros aspectos da teoria do núcleo central conforme expõe Pereira de Sá (1996, apud Guimarães, 2005): I) a transformação das representações - que se inicia pela periferia, decorrente das modificações nas práticas sociais. 
II) a comparação das representações - pode-se comparar representações mantidas por dois grupos diferentes ou por um mesmo grupo em momentos distintos. A referida teoria oferece $o$ critério de que serão diferentes se - e apenas -se os núcleos centrais tiverem evocações significativamente diferentes.

Segundo Mazzotti (2007, p. 582) o núcleo central forma a base da representação, é indispensável a sua identificação para que se possa avaliar a homogeneidade de um grupo. Nesta perspectiva, somente é possível "afirmar que dois ou mais grupos têm a mesma representação de um objeto se estes partilharem o mesmo núcleo central; não basta que as representações apresentem os mesmos elementos; se os núcleos forem diferentes, elas serão diferentes".

Ademais, o NC desempenha três funções fundamentais: "(a) função geradora - ele é o elemento pelo qual se cria e se transforma uma representação; (b) função organizadora - é ele que determina a natureza das ligações entre os elementos de uma representação; e (c) função estabilizadora - seus elementos são os que mais resistem à mudança" (MAZZOTTI, 2007, p. 582). Os outros elementos que compõem as representações - os elementos periféricos, constituem a parte operatória da representação, exercem um papel significativo no funcionamento e na dinâmica das representações. Guimarães (2005) comenta que a heterogeneidade da periferia não indica a existência de representações diferentes, indica futuras alterações ou indícios de evolução nas situações onde há processo de transformação em curso.

Diante das definições e de tudo que foi exposto, é importante entender as representações sociais que os alunos ingressantes e concluintes de um curso de Pedagogia possuem sobre "o que é ser professor na atualidade", frente às novas demandas e aos desafios que a educação básica enfrenta se torna imprescindível para imprimir uma maior qualidade nos cursos de formação docente.

\section{RESULTADOS}

As associações livres à palavra indutora "ser professor hoje" - EVOC geral

As associações com a expressão "ser professor hoje" produziram nos 68 alunos da amostra total, 338 palavras, dentre as quais 124 são evocações diferentes. Por meio do programa
Rangmot do EVOC, observou-se que $52,4 \%$ das palavras enunciadas (177) não tiveram uma frequência mínima maior que cinco e, portanto, não foram consideradas relevantes para a análise da composição do núcleo central. Para a análise do núcleo central considerou-se as palavras que obtiveram uma frequência maior que 12 e uma ordem de evocação menor que 2,9 - média geral das palavras (moyenne generale).

Ao considerar os alunos ingressantes juntamente com os concluintes, observamos que suas representações estiveram centradas na: responsabilidade. Esse aspecto torna evidente a consciência dos discentes em relação ao seu futuro papel como docentes, uma vez que os participantes compreendem a grande responsabilidade que é ser professor. Essa compreensão traduz a responsabilidade que há na reflexão sobre o que ensinar, como ensinar e para que ensinar, numa constante avaliação de suas atitudes e ações diante das funções que lhe atribuem no cotidiano escolar.

É importante salientar que o professor não trabalha sozinho, no entanto é esse profissional que passa a maior parte do tempo em contato com os alunos em sala de aula. Portanto, cabe ao docente desenvolver as potencialidades de cada aluno. Ademais, compõe o núcleo central um fator importante nas representações sociais dos discentes: a competência do professor, isso indica que para os alunos ser professor, principalmente hoje, exige ser competente em suas atribuições em sala de aula e em todo o âmbito escolar. Integrase ainda à estrutura das representações: a dedicação e o respeito aos alunos, demais integrantes da comunidade escolar e sociedade como um todo. Cabe ainda ressaltar que as palavras destacadas, encontram-se no primeiro quadrante do programa RANGFRQ, que representa as palavras mais frequentes e citadas nos primeiros lugares, e que correspondem ao núcleo central.

Por sua vez, as palavras evocadas que se encontram no segundo quadrante indicam que ser professor é praticar o amor. De acordo com os discentes do curso de Pedagogia, para ser professor é necessário ter amor à profissão. Além disso, consideram que ser professor hoje requer paciência, requer ainda que a ética conduza as atitudes dos docentes. É fundamental ressaltar, que as palavras do segundo quadrante em destaque referem-se às palavras localizadas na "periferia" próxima ao núcleo central, que 
tiveram uma frequência considerável, porém, foram evocadas tardiamente.

Comparação entre as representações sociais dos alunos ingressantes e concluintes

Os dados das associações livres da expressão "ser professor hoje", relacionados aos discentes ingressantes produziram um total de 190 palavras, sendo 77 palavras diferentes. Para a análise do núcleo central, foram consideradas as evocações com frequência maior ou igual a 10 e ordem de posição (rang moyen- classificação média) menor que 3.

Quando comparadas as representações dos alunos ingressantes separadamente das representações dos alunos concluintes observamos que as associações de palavras dos discentes ingressantes foram semelhantes aos elementos do núcleo central apresentado na análise do EVOC geral, diferentemente dos concluintes. $\mathrm{Na}$ análise dos elementos estruturais do núcleo central dos discentes ingressantes, evidencia-se que a atividade docente deve ser realizada com responsabilidade e com dedicação, na qual as relações devem ser mediadas por meio do respeito e do amor.

Tabela 1. Núcleo central e periférico das representações. Programa RANGFRQ

\begin{tabular}{l|lll|lcc}
\hline & Evocação & $\mathbf{F}_{\mathbf{x}}$ & OME<3 & Evocação & $\mathbf{F}_{\mathbf{x}}$ & OME >=3 \\
\hline \multirow{3}{*}{ Frequência $>=10$} & Dedicação & 14 & 2,857 & Amor & 18 & 3,333 \\
& Respeito & 10 & 1,800 & & & \\
& Responsabilidade & 16 & 2,375 & & & \\
\hline
\end{tabular}

Ao observar a imagem, nota-se que há contradição entre o critério de posição (rang/ou rank) e o de frequência. Esse fato ocorre devido a ordem de posição em que a palavra foi citada. É evidente que a palavra amor foi citada com uma maior frequência do que as palavras evocadas que compõem o núcleo central das representações sociais (1으 quadrante). No entanto, a palavra se encontra na periferia próxima, pelo fato de aparecer em uma ordem de importância sempre inferior as demais palavras do 10 quadrante.

Em relação aos alunos concluintes, os dados produziram um total de 148 palavras, sendo 77 palavras diferentes. Para a análise do núcleo central, também foram consideradas as evocações com frequência maior ou igual a 10 e ordem de posição menor que 3 .

Observa-se na tabela 2 que o núcleo central das representações dos alunos (concluintes) é composto por um único elemento - competência, o que indica o sentimento "dever" a cumprir dos futuros profissionais em relação a sua carreira, pois consideram que devem ser competentes no desempenho de sua função. Afinal, todo docente que visa ser competente, que busca ser um bom profissional deve ter domínio dos conteúdos que se propõe a ensinar bem como dos conhecimentos de mundo dos alunos, além de ter um bom preparo didático pedagógico. Na composição da periferia estão as palavras ética e responsabilidade.

Tabela 2. Núcleo central e periférico das representações. Programa RANGFRQ

\begin{tabular}{l|lcc|lccc}
\hline & Evocação & $\mathbf{F}_{\mathbf{x}}$ & OME<3 & Evocação & F & OME >=3 \\
\hline \multirow{2}{*}{ Frequência $>=10$} & Competência & 13 & 2,385 & Ética & 10 & 3,600 \\
& & & & Responsabilidade & 6 & 3,667 \\
\hline
\end{tabular}

Considerando os elementos que formam a estrutura do núcleo central das representações sociais dos discentes concluintes, nota-se que houve alterações em relação a frequência e ordem das evocações quando comparadas com as associações dos alunos ingressantes.
Deste modo, pode-se dizer que as representações dos discentes concluintes são diferentes das representações dos discentes ingressantes, no que se refere ao núcleo central e ao sistema periférico. Diante da análise dos dados observou-se que houve modificações nas 
representações sociais dos alunos em relação ao tempo de permanência e experiência no curso de licenciatura em Pedagogia.

\section{DISCUSSÃO}

É relevante destacar que os resultados indicaram diferenças significativas entre as representações dos dois grupos (ingressantes) e (concluintes), refletidas na configuração de seus núcleos.

Observa-se que os questionamentos, as dúvidas sobre a formação e sobre o que é ser professor na atualidade são mutáveis e evoluem por meio da prática social. Dessa forma, os resultados apontam na direção de que há uma evolução das representações sociais dos participantes entre os iniciantes e os concluintes. Ademais, percebe-se que essa evolução ocorre dentro do espaço de representação, e não como construção de uma nova representação do objeto de estudo - ser professor hoje.

Ao analisar as evocações do núcleo central das representações dos alunos ingressantes: responsabilidade, dedicação $e$ respeito, podemos observar que há uma certa preocupação em relação a grande responsabilidade que é ser professor. Os alunos (iniciantes) ressaltam que escolherem a palavra responsabilidade pois quando se trata do professor, muitos aspectos são envolvidos, tais como a escola, os alunos, as aulas. E, que para ser um bom profissional deve-se ter responsabilidade para assumir sua posição como docente. Ressaltam ainda que, o docente, no seu papel de "líder" deve conduzir os alunos por meio de um bom ensinamento, e que por isso o grau de responsabilidade do professor é alto e deve ser tomado como prioridade. As palavras dedicação $e$ respeito nos faz inferir que os estudantes em início de formação se atentam para o modo como vão atuar em sala de aula e para a maneira como vão se relacionar com os alunos, revelam um sentimento mais tradicional, relacionado à função docente. Para os alunos iniciantes, ser professor é ser responsável pelas futuras gerações que irão nos representar.

Em relação aos alunos concluintes, o núcleo central, constituído por apenas um elemento - a palavra competência, ressalta que os alunos concluintes, por suas vivências e experiências no decorrer do curso se preocupam primordialmente com as competências e habilidades que o professor deve desenvolver para que suas funções sejam desempenhadas de forma mais consciente e coerente. Segundo os alunos (concluintes) o professor necessita ter competência para lidar com os desafios que encontram na sala de aula. Além disso, discorrem que o docente contemporâneo deve ter o domínio dos conteúdos específicos da área educacional e desenvolver as habilidades necessárias para atuar de forma precisa no processo de ensino-aprendizagem. Para os alunos concluintes ser professor é ter a competência em assumir sua função de ensinar ao mesmo tempo em que aprende.

As análises dos dados apontam que a formação inicial pode possibilitar um novo modo de perceber e vivenciar dada realidade. Desde a formação inicial, os futuros docentes trazem consigo próprias representações e de alguma forma as processa. Tais representações estão fincadas nos diversos momentos vivenciados no processo de escolarização. Para Nóvoa (1992), é fundamental que as instituições formadoras considerem essas representações, de ordem social e pessoal, possibilitando ainda que os futuros docentes conheçam melhor a si próprios e a realidade da profissão que irão assumir.

Cabe considerar ainda, segundo Jodelet (1993), que as representações sobre o trabalho docente que os professores ou futuros professores possuem, podem coexistir com os conhecimentos que receberam (ou recebem) em sua formação inicial, como também se constituírem em obstáculos ou mecanismos de resistência para novos conhecimentos. Essas mesmas representações podem impedir mudanças mais efetivas, ficando apenas na superfície, sem possibilitar que haja uma transformação capaz de atender as atuais demandas formativas e educacionais (ABRIC, 1994).

Nesse sentido, é de fundamental importância que as instituições de ensino cultivem o hábito de ouvir o que os alunos pensam, de conhecer suas representações sobre o que é ser professor na atualidade. Para a partir desse ponto, pensar em uma organização curricular na formação inicial que atenda aos desafios da contemporaneidade.

\section{CONSIDERAÇÕES FINAIS}

Os resultados dessa pesquisa, que se apoiou na teoria das representações sociais, permitiram uma maior compreensão da 
complexidade sobre "ser professor", por meio da análise das respostas de alunos ingressantes e concluintes de um curso de pedagogia. Constatou-se que as representações sociais dos referidos estudantes sobre ser professor estão associados atributos como: competência, dedicação, ética e amor a profissão e ao próximo. Esses atributos revelados nas falas dos sujeitos da pesquisa se configuram como fatores imprescindíveis a uma prática docente pautada numa visão de educação que aponta escola mais democrática, justa e humana.

O professor deve ter consciência da importância do seu papel transformador, capaz de proporcionar ao seu aluno diversos conhecimentos, fazendo com que esse aluno seja consciente e autônomo para e na sociedade. A relação dos professores com a sua prática constitui uma reflexão essencial para a atividade docente. Sendo fundamental a formação de indivíduos pensantes e críticos. Por isso devemos pensar a formação de um profissional da educação como alguém que compreenda os fundamentos das ciências, revele uma visão ampla dos saberes e que pratique um processo de ensino/aprendizagem reflexivo, conforme afirma Pimenta (1997).

Deste modo, todo professor deve buscar uma formação contínua e sempre refletir sobre e na sua prática, para que ele possa proporcionar aos seus alunos uma troca de conhecimentos e uma mediação dos mesmos. Formar indivíduos pensantes e conhecedores de seus direitos e deveres deve ser o principal foco do professor, para que assim, todos os alunos tenham um processo de ensino/aprendizado de qualidade. Em relação à formação de professores, quando se há uma preocupação com esse processo, mostrase que os docentes têm uma importante e significativa contribuição social, que influencia diretamente na formação "de indivíduos pensantes". Quando os saberes docentes são respeitados e valorizados, há uma motivação para se ensinar, para que o professor possa mediar de forma qualificada o conhecimento e o diálogo dentro do âmbito escolar.

Por fim, espera-se que essa pesquisa sobre as representações sociais do ser professor, possa se ampliar para outros estudos que contribuam para a compreensão de como o curso de pedagogia pode se constituir um espaço de formação docente que propicie 0 desenvolvimento de saberes e competências que atendam as demandas de uma sociedade mais justa e inclusiva.

\section{REFERÊNCIAS}

ABRIC, J.C. A abordagem estrutural das representações sociais. In: MOREIRA, A. S. P.; OLIVEIRA, D. C. de (Orgs.). Estudos Interdisciplinares de Representação Social. 2 ed. Goiânia: AB, 1994, p. 27-38.

GEBRAN, Raimunda Abou; TREVISAN, Zizi. As representações sociais na construção da identidade profissional e do trabalho docente. [S.I.]: [s.n.], 2015.

GUIMARÃES; Célia Maria Aplicabilidade das Representações Sociais ao Estudo de Fenômenos Educacionais: mudar as práticas de formação para mudar as práticas educativas do profissional de educação infantil. In: GUIMARÃES, Célia Maria (org.). Perspectivas para educação infantil. Araraquara, SP: Junqueira \& Marin, 2005.

JODELET, Denise. Representações sociais: um domínio em expansão. In: JODELET, D. (Org.). As representações sociais. Rio de Janeiro: UFRJ, 1993. p. 1-21.

MAZZOTTI, Alda Judith Alves. Representações da identidade docente: uma contribuição para a formulação de políticas. Ensaio: Aval. Pol. Públ. Educ., Rio de Janeiro, v. 15 , n. 57, p. 579-594, out./dez. 2007.

MAZZOTTI, Alda Judith Alves. Representações Sociais: aspectos teóricos e aplicações à educação. Revista Múltiplas Leituras, v.1, n. 1, p. 18-43, jan. / jun. 2007. Disponível em: https://www.metodista.br/revistas/revistasims/index.php/ML/article/view/1169. Acesso em: 01 fev. 2016.

MARCELO, Carlos. A identidade docente: constantes e desafios. Revista Formação Docente, Belo Horizonte, v. 1, n. 1, p. 109-131, ago./dez. 2009. Disponível em: http://formacaodocente.autenticaeditora.com.br /artigo/exibir/1/3/1. Acesso em: $01 \mathrm{fev} .2016$

MENIN, M. S. S.; ZECHI, J. A. M. Versão em português do Manual do EVOC 2000 de Pierre Vergès de 15 de outubro de 2003. Presidente Prudente: UNESP, 2009.

MOSCOVICl, Serge. Representações sociais: investigações em psicologia social. Tradução de Pedrinho Guareschi. 11. ed. Petrópolis/RJ: Vozes, 2015.

NÓVOA, A. Profissão professor. Lisboa: Porto Ed., 1992.

PIMENTA, Selma G. Formação de Professores: saberes da docência e identidade do professor. 
Nuances, v. 3, set. 1997. Disponível em: http://revista.fct.unesp.br/index.php/Nuances/ar ticle/download/50/46. Acesso em: 20 jun. 2015.

Recebido para publicação em 19/08/2016

Revisado em 27/08/2016

Aceito em 30/08/2016 